\title{
Toxicity responses for marine invertebrate species of brazilian occurrence
}

\author{
Artal, M.C. ${ }^{1}$; Santos, A. ${ }^{1}$; Dornelas, L.L. ${ }^{2}$; VAnnuCi-Silva, M. ${ }^{3}$; VACChi, F.I. ${ }^{3}$; De AlbuQuerQue, A.F. ${ }^{2}$; \\ Lotufo, G.R. ${ }^{4}$ \& UMbUZEIRO, G.A. ${ }^{1,2,3}$ \\ ${ }^{1}$ School of Pharmaceutical Sciences, University of São Paulo, São Paulo, Brazil. \\ ${ }^{2}$ School of Technology, University of Campinas, Limeira, Brazil. \\ ${ }^{3}$ Institute of Biology, University of Campinas, Campinas, Brazil. \\ ${ }^{4}$ U.S. Army Engineer Research and Development Center, Vicksburg, USA.
}

Received February 26, 2019; Accept June 19, 2019

\begin{abstract}
To assess the risk of chemical contaminants it is desirable to derive toxicity data from representative species of the ecosystem intended to be protected. However, species of occurrence in Brazil are rarely used in toxicity tests, especially for marine and estuarine environments. To address this need, we evaluated the toxicity of different toxicants such as metals and organic compounds to marine invertebrates of Brazilian occurrence, representative from tropical regions and cultivated in laboratory. We used two epibenthic test species of Brazilian occurrence, Parhyale hawaiensis, a deposit feeding amphipod and Nitocra sp, a harpacticoid copepod. Nitocra sp. was more sensitive than other copepods to zinc, and more sensitive than P. hawaiensis to disperse dyes. Sensitivity species distribution revealed that Nitocra sp. and P. hawaiensis were similarly responsive as other marine species to zinc, and Nitocra sp. was among of the most sensitive species. Moreover, our study highlighted that organic compounds are poorly explored in toxicity evaluation with marine organisms; therefore, more studies need to be carried out to assess the toxicity of different substances using marine and estuarine organisms representative of tropical ecosystems.
\end{abstract}

Keywords C. I. Disperse Red 1, C. I. Disperse Red 13, Metals toxicity, Nitocra sp., Parhyale hawaiensis, Pirimiphos-methyl.

\section{INTRODUCTION}

Contaminants are widespread in aquatic environments in Brazil (Seabra et al., 2016) and environmental risk assessment is an important tool for evaluation and management of pollution. Risk assessment of contaminants includes biological effect assessment which is often based on acute and chronic laboratory tests of the toxicity of these compounds to aquatic species (Teklu et al., 2016). To carry out toxicity tests it is desirable to use species that are representative of the ecosystem to be protected; however, technical norms for toxicity testing in Brazil exist for only few marine species, and species of occurrence in Brazil are rarely used in toxicity tests (Melo \& Nipper, 2007; Krull \& Barros, 2012; ABNT,
2016). In addition to the lack of representative species, toxicity assessments often depend on the results of toxicity tests performed with temperate species, as data on tropical species are scarce (Kwok et al., 2007). Risk assessments performed for tropical ecosystems should be based on toxicity data from tropical species, since differences in sensitivity might be expected (Daam \& Brink, 2010; Klok et al., 2012).

To fulfill the gap of toxicity tests using marine and tropical species of occurrence in Brazil, several studies have been conducted with different species in the last years (Sousa et al., 2014). The majority of studies were conducted with crustaceans that are well recognized to be sensitive to several contaminants, have widespread distribution and are easy to handle. However, most studies were carried out with field- 
collected organisms, which generally show significant seasonal variations in abundance and health status, and their response in toxicity tests may be influenced by abiotic factors such as water temperature and salinity (McGee et al., 1998). Another point of concern is that toxicity data for individual pollutants derived using Brazilian test species are scarce, making risk assessment for tropical environments less realistic.

To address the urgent need to expand the available tropical marine species for use in toxicity testing, our laboratory has implemented culture conditions and developed toxicity tests for Parhyale hawaiensis (Artal et al., 2018), a deposit-feeding amphipod with circumtropical distribution and inhabits intertidal, mangrove and shallow waters of the Brazilian coast. $P$. hawaiensis was chosen because it is well established as a model in developmental and evolutionary studies (Kao et al., 2016) and recently successfully used in ecotoxicity tests (Artal et al., 2018). Another tropical and representative species is Nitocra sp., a harpacticoid copepod that inhabits region between mangrove swamps, and its culture was implemented in 1998 from organisms collected on sediment surface from intertidal zone of Spartina sp. banks in Cananéia Estuary, southern coast of the state of São Paulo (Lotufo \& Abessa, 2002; Sousa et al., 2012), and it was chosen for being easy to handle and well established as a test organism.

The aim of this work was to contribute with the literature presenting toxicity data of some metals and organic compounds tested with $P$. hawaiensis and Nitocra sp., marine invertebrates of Brazilian occurrence, representative from tropical regions, maintained in laboratory conditions.

\section{MATERIAL AND METHODS}

Data from this work have not been published elsewhere, they were obtained in different projects developed in the Laboratory of Ecotoxicology and Genotoxicity (LAEG) during the last ten years.

\section{Chemicals}

We used as testing substances four metals (silver, cadmium, copper and zinc) and three organic compounds, two dyes (C.I. Disperse Red 1, C.I. Disperse Red 13) and the pesticide Pirimiphos-methyl. All substances were tested with P. hawaiensis, but for Nitocra sp., only zinc, C.I. Disperse Red 1, C.I. Disperse Red 13 were used. Because the data were obtained from different projects, the testing conditions varied according to the objective of each study.

For toxicity tests with silver, silver nitrate was used $\left(\mathrm{AgNO}_{3}\right.$, Sigma-Aldrich ${ }^{\circledR}, \geq 99 \%$ purity, CAS $\left.7761-88-8\right)$ because it releases ionic silver $\left(\mathrm{Ag}^{+}\right)$, the most toxic silver form for aquatic organisms, and it is soluble in water (Asghari et al., 2012). Zinc sulfate heptahydrate $\left(\mathrm{ZnSO}_{4} \cdot 7 \mathrm{H}_{2} \mathrm{O}\right.$, Ecibra ${ }^{\circledR}$, $\geq 99 \%$ purity, CAS 7446-20-0) was used as a source of zinc, cadmium nitrate tetrahydrate $\left(\mathrm{Cd}\left(\mathrm{NO}_{3}\right)_{2} .4 \mathrm{H}_{2} \mathrm{O}\right.$, Vetec $\AA$, $99 \%$ purity, CAS 10022-68-1) for cadmium and copper (II) chloride dihydrate $\left(\mathrm{CuCl}_{2} .2 \mathrm{H}_{2} \mathrm{O}\right.$, Sigma-Aldrich ${ }^{\circledR}, \geq 99 \%$ purity, CAS
10125-13-0) for copper. Concentrations were expressed in mass of ions per volume of test solution for all metals.

The azo dyes C.I. Disperse Red 1 and C.I. Disperse Red 13 were selected to be tested due to its recognized toxicity. They have similar structures and differ by the presence of a chlorine atom at C. I. Disperse Red 13. These dyes have been reported to be toxic to freshwater organisms and have been observed in surface waters in Brazil (Ferraz et al., 2011; Vacchi et al., 2016). C. I. Disperse Red 1 (commercial product) was purchased from PCIL ${ }^{\circledR}$ Chemicals Industries LTDA and has as main product the dye Disperse Red 1 ( $N$-Ethyl- $N(2-$ hydroxyethyl)-4-(4-nitrophenylazo) aniline, CAS 2872-52$8)$. The commercial product used in this study was the same characterized by Vacchi et al. (2013), containing $60 \%(\mathrm{~m} / \mathrm{m})$ of primary dye, $20 \%$ of residual dyes from synthesis and $20 \%$ of synthetic surfactant and whose toxicity was attributed to the main dye. C. I. Disperse Red 13 (2-[4-(2-Chloro-4nitrophenylazo)- $N$-ethylphenylamino] ethanol, CAS 3180$81-2$ ) with $25 \%$ purity was purchased from Sigma-Aldrich ${ }^{\circledR}$ and despite the low purity toxicity data was include because in this work the main objective was to compare the responses of the two testing organisms. We analysed the dye product using thin layer chromatography (data not shown), and no other dyes appeared, which suggests the presence of surfactants usually aided to those dyes to facilitate solubility.

The pesticide pirimiphos-methyl (CAS 29232-93-7) used for testing was bought from Sigma-Aldrich ${ }^{\circledR}$ (Seelze/German), purity $>98 \%$. Pirimiphos-methyl is an organophosphorus insecticide and acaricide used to control different pests. Its use is approved in Brazil for foliar application in lettuce, citrus, kale, beans, pods and for application to stored rice, barley, corn and wheat (MAPA, 2019). The toxicity of this pesticide has already been tested in freshwater organisms such as algae, daphnia and fish (Lewis et al., 2016), but no toxicity data were found for marine organisms.

All testing solutions were prepared using reconstituted seawater (Red Sea Salt, Red Sea $\left.{ }^{\circledR}\right)$.

\section{Parhyale hawaiensis - culture and testing conditions}

Culture and testing conditions for $P$. hawaiensis followed the protocol established by Artal et al. (2018). Reconstituted seawater was used in the cultures and prepared with marine salt (Red Sea Salt, Red Sea ${ }^{\circledR}$ ) dissolved in deionized water to achieve the desired salinity. Water quality parameters such as dissolved oxygen (YSI Incorporated $\AA$, 55/12), salinity

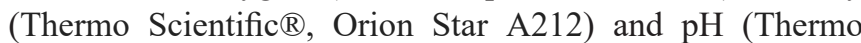
Scientific ${ }^{\circledR}$, Orion Star A211) were measured in each prepared new batch of water.

Organisms were kept at a constant temperature of $24 \pm$ $2{ }^{\circ} \mathrm{C}$ and photoperiod of $12 \mathrm{~h}$ light: $12 \mathrm{~h}$ dark, under constant aeration, in plastic container containing crushed coral, filled with reconstituted seawater. Organisms were fed with pellets of commercial fish food (Novo fect, JBL $®) 5$ times per week. Culture was maintained at salinity $30 \pm 2$ in reconstituted seawater and partial water exchanges were performed twice 
per week. Additional cultures were maintained at salinity 5 for specific experiments and were maintained as described above. According to Artal et al. (2018), two protocols of toxicity tests presented comparable results, one used vials of containing 25 $\mathrm{mL}$ of test solution and another using microplates with $200 \mu \mathrm{L}$ of test solution in each well (miniaturized conditions). In this work we reported data with both protocols.

In all experiments neonates ( $\leq 7$ days-old) were used in the toxicity tests except for silver. In this case we used adults ( $>8$ months-old) because we needed to determine nonlethal concentrations for adults that were being used for the determination of silver internal doses (hemolymph), as reported by Vannuci-Silva et al. $(2018,2019)$. Toxicity tests were performed in static conditions, for $96-\mathrm{h}$, at $24^{\circ} \mathrm{C} \pm 2$ temperature, $12 \mathrm{~h}$ light:12 h dark and no feeding. For silver exposure, 10 replicates per concentration, with 1 organism per replicate were used. Each organism was exposed in a clean plastic container with $100 \mathrm{~mL}$ of reconstituted seawater (control) or a solution with seawater and $\mathrm{AgNO}_{3}$ at different concentrations, and tests were conducted in salinities 5 and 30. Silver nominal concentrations were $0.025,0.05,0.08,0.1,0.2,0.25 \mathrm{mg} \mathrm{L}^{-1}$ for salinity 5 , and $0.001,0.01,0,1,0.25,0.5,1,2,4,8,10 \mathrm{mg} \mathrm{L}^{-1}$ for salinity 30 . Zinc, cadmium and copper tests were conducted using a miniaturized testing approach develop by Artal et al. (2018). Neonates were placed in 96-well microplates, with 32 replicas per concentration, 1 organism per well, in $200 \mu \mathrm{L}$ of testing solution. Nominal concentrations were $0.125,0.25,0.5$, $1,2,4 \mathrm{mg} \mathrm{L}^{-1}$ for zinc; $0.1,0.2,0.3,0.4,0.8,1.6 \mathrm{mg} \mathrm{L}^{-1}$ for cadmium and $0.2,0.4,0.8,1.6,3.2 \mathrm{mg} \mathrm{L}^{-1}$ for copper.

Toxicity tests with dyes were performed with higher volumes of test solution according to Artal et al. (2018). For each of 10 replicates, one neonate ( $\leq 7$ days-old) was exposed to the dyes for 96 -h at $24 \pm 2{ }^{\circ} \mathrm{C}$ in a $25 \mathrm{~mL}$ plastic container, with a $12 \mathrm{~h}$ light: $12 \mathrm{~h}$ dark photoperiod and salinity 30 . Stock solutions were dissolved in dimethyl sulfoxide (DMSO, $\left(\mathrm{CH}_{3}\right)_{2} \mathrm{SO}$, Sigma-Aldrich ${ }^{\circledR}, 99.5 \%$ purity, CAS 67-68-5) to increase solubilization and successive dilutions were prepared in reconstituted seawater. Nominal concentrations used to test C.I. Disperse Red 1 and C.I. Disperse Red 13 were $0.2,1,5$, $25,125 \mathrm{mg} \mathrm{L}^{-1}$ and $0.1,0.3,0.9,2.7,8.1 \mathrm{mg} \mathrm{L}^{-1}$, respectively.

Pirimiphos-methyl toxicity tests were conducted with neonates ( $\leq 7$ days-old) in the miniaturized protocol with 96well microplate, using the same conditions described above. Stock solution of pirimiphos-methyl was prepared in DMSO to increase solubility, and successive nominal concentrations $(0.1$, $\left.0.25,0.5,0.75,1 \mathrm{mg} \mathrm{L}^{-1}\right)$ were prepared in reconstituted seawater.

Tests in the presence of solvent (DMSO) did not exceed $0.1 \%(\mathrm{v} / \mathrm{v})$ of the solution volume and were carried out with controls held in parallel. After a 96-h exposure, dead organisms were counted, and tests were considered valid if mortality did not exceed $10 \%$ in the negative controls.

\section{Nitocra sp. - culture and testing conditions}

Organisms were obtained from the Laboratory of Marine Ecotoxicology and Microphytobenthic (LEcotox) of the
Oceanographic Institute of the University of São Paulo in Brazil. The culture of Nitocra sp. is monospecific and was established in 1998 from organisms collected on the sediment surface from the intertidal zone in the Cananéia Estuary in the southern coast of the state of São Paulo (Lotufo \& Abessa, 2002; Sousa et al., 2012). Nitocra sp. is a benthic estuarine (salinity varying between 5 and 30) harpacticoid copepod (Lotufo \& Abessa, 2002). Organisms were cultivated in laboratory conditions according to Lotufo \& Abessa (2002). Organisms were maintained at a constant temperature of $24 \pm 1{ }^{\circ} \mathrm{C}$ and photoperiod of $12 \mathrm{~h}$ light: $12 \mathrm{~h}$ dark, without aeration, in 500 and $1000 \mathrm{~mL}$ Erlenmeyer flasks covered with gauze and cotton, fed fermented Tetramin ${ }^{\circledR}$ fish food twice per week. Copepods were cultured at different salinities $(5,10$ and 20) in reconstituted seawater and partial water exchanges were performed periodically. Reconstituted seawater was used in the cultures and prepared with marine salt (Red Sea Salt, Red Sea $\left.{ }^{\circledR}\right)$ dissolved in deionized water to achieve the desired salinity. Water quality parameters such as dissolved oxygen (YSI Incorporated $\AA$, 55/12), salinity (Thermo Scientific $\AA$, Orion Star A212) and pH (Thermo Scientific ${ }^{\circledR}$, Orion Star A211) were measured in each prepared new batch of water.

Stock solutions prepared for dyes testing were made in ultrapure water following successive dilutions in reconstituted seawater at salinity 20 , not exceeding $10 \%$ of the solution volume. For zinc, solutions were prepared directly in reconstituted seawater with successive dilutions. Toxicity tests assessing the mortality of copepods were conducted with dyes and zinc in 12-well microplates, with salinity $20 \pm 2$, with $5 \mathrm{~mL}$ of testing solution in each well and 10 adult organisms without egg sacks in each replicate. Dyes tests were conducted with 4 replicates for each concentration and zinc with 3 replicates. Organisms were exposed for $96-\mathrm{h}$ at $24 \pm 1{ }^{\circ} \mathrm{C}$, with a $12 \mathrm{~h}$ light: $12 \mathrm{~h}$ dark photoperiod. After $96-\mathrm{h}$ exposure period, the immobilized organisms were counted under a stereo microscope. Tests were considered valid if mortality was less than $10 \%$ in the negative control. Nominal concentrations used to test zinc were from 0.1 to $2.3 \mathrm{mg} \mathrm{L}^{-1}$, for C.I. Disperse Red 1 were $0.05,0.1,0.5,1,2.5$, $5 \mathrm{mg} \mathrm{L}^{-1}$ and for C.I. Disperse Red 13 were $0.01,0.05,0.1,0.5$, $1,2.5,5 \mathrm{mg} \mathrm{L}^{-1}$.

Egg hatching success tests were performed based on Lotufo \& Abessa (2002) with some modifications. Tests were performed with $2 \mathrm{~mL}$ solution in 24-well plates, ten replicates, one ovigerous female per replicate, 96-h exposure, temperature $24 \pm 1{ }^{\circ} \mathrm{C}$ and photoperiod of $12 \mathrm{~h}$ light: $12 \mathrm{~h}$ dark. At the end of the exposure, the number of hatching eggs, assessed as the number of nauplii, were recorded under a stereoscopic microscope. Nominal concentrations used to the egg hatching success test were $0.11,0.23,0.46,0.68,1.14 \mathrm{mg}$ $\mathrm{L}^{-1}$ for zinc and $0.1,1,2,3,5 \mathrm{mg} \mathrm{L}^{-1}$ for C.I. Disperse Red 1 and C.I. Disperse Red 13.

\section{Statistical analysis}

Individual toxicity tests for the same substance were combined for the median lethal concentration (LC50) 
determination, and the observed mortality of organisms was modeled by logistic regression with the following generalized logistic model: logit $(P)=\mu+\mathrm{b}$ (concentration), where logit $(P)$ is the log odds of an organism dying, $\mu$ is an intercept value, and b is the fixed effect of concentration. Model estimation was performed by iterative estimation of the likelihood function. The estimate of logit $(P)$ was used to obtain the predicted probability of mortality $(P)=\operatorname{elogit}(P) /$ $(1+\operatorname{elogit}(P))$. For comparison of number of hatching nauplii among concentrations, data were determined using ANOVA after it was determined to be normally distributed (ShapiroWilks test, $p>0.05$ ) with homogeneous variance (Bartlett test $p>0.05$ ), and differences among levels of the independent variable were determined by Tukey's test post hoc ( $p>$ 0.05). The no-observed-effect concentration (NOEC) value determined is the highest tested concentration at which no measured biological parameter is statistically different from the control $(p<0.05)$. Statistical analysis was performed using the computing environment $\mathrm{R}$ (R Core Team, 2017). In addition, $10 \%$ effective concetration (EC10) values were estimated using the MOSAIC web-interface for statistical analyses in ecotoxicology (Charles et al., 2017). MOSAIC is available at http://pbil.univ-lyon1.fr/software/mosaic/.

\section{Species sensitivity distribution modeling}

Species sensitivity distribution (SSD) curves were fitted with Excel ${ }^{\circledR}$ macro "SSD generator V1" (USEPA, 2017) using the acute LC50-values derived from the concentrationresponse curves, in the case of $P$. hawaiensis and Nitocra sp., and toxicity data obtained from ECOTOX knowledgebase V5 (USEPA, 2019) for other species. Ecotoxicity data were chosen from the US Environmental Protection Agency (USEPA) database according to the following conditions: LC50 endpoint, saltwater, static condition, standard species and available reference. From a regulatory perspective, SSD model is used to calculate a chemical concentration protective of most species in the environment. However, in the present study, we used SSD to compare sensitivity of marine organisms to zinc.

\section{RESULTS AND DISCUSSION}

Disperse dyes presented visual precipitation during the toxicity test at concentrations $>1 \mathrm{mg} \mathrm{L}^{-1}$ despite efforts to increase the dissolution of dyes in stock solution using ultrapure water and DMSO as solvent. This fact decreases concentration available in solution, but could increase the exposure of organisms in contact with the bottom, like organisms such as P. hawaiensis and Nitocra sp. Precipitation and agglomeration of C. I. Disperse Red 1 in solution were previously reported by Ribeiro \& Umbuzeiro (2014) in higher concentrations for freshwater toxicity tests using the flatworm Girardia tigrina. Furthermore, it was observed red color inside and precipitated dye attached to the exposed organisms. The same observation was made by $\mathrm{Yu}$ et al. (2015) in Daphnia similis exposed to C.I. Disperse Red 1, showing the uptake of dyes by organisms.
Effects observed for different substances for $P$. hawaiensis were described in Table 1 (see Supplemental Data I for raw data). LC50 value estimated for cadmium was $0.45 \mathrm{mg} \mathrm{L}^{-1}$, and it is consistent with results observed by Artal et al. (2018) with LC50 of $0.5 \mathrm{mg} \mathrm{L}^{-1} \mathrm{Cd}$ for the same organism and testing conditions. Comparisons were made to the available literature for marine amphipods exposed to cadmium: Melita plumulosa showed a LC50 value of $0.52 \mathrm{mg} \mathrm{L}^{-1} \mathrm{Cd}$ (King et al., 2006a) and Leptocheirus plumulosus of $0.3 \mathrm{mg} \mathrm{L}^{-1} \mathrm{Cd}$ (McGee et al., 1998). P. hawaiensis sensitivity to cadmium was within the range of other amphipods and this result corroborates with Artal et al. (2018), who reported that $P$. hawaiensis is as sensitive as other amphipods comparing the toxicity of different metals and ammonia. Nonetheless, comparing copper toxicity data obtained for $P$. hawaiensis, performed in the same conditions, with a LC50 of $2.46 \mathrm{mg} \mathrm{L}^{-1} \mathrm{Cu}$ in this study and $1.7 \mathrm{mg} \mathrm{L}^{-1} \mathrm{Cu}$ reported by Artal et al. (2018), $P$. hawaiensis was less sensitive than Melita plumulosa and the Australian and New Zealand amphipods, which presented a LC50 of $0.1 \mathrm{mg} \mathrm{L}^{-1} \mathrm{Cu}$ with same testing conditions (age, photoperiod, salinity and time of exposure) with the exception of temperature $\left(21^{\circ} \mathrm{C}\right)$ that could influence the toxicity (King et al., 2006a; King et al., 2006b). McPherson and Chapman (2000) reviewed the literature to discuss the sensitivity of marine and estuarine organisms for copper and showed that Ampelisca abdita was the most sensitive amphipod with a 168-h LC50 of $0.09 \mathrm{mg} \mathrm{L}^{-1} \mathrm{Cu}$ and Corophium volutator the least sensitive with $96-\mathrm{h} \mathrm{LC50}$ of $32 \mathrm{mg} \mathrm{L}^{-1} \mathrm{Cu}$. Despite the comparison, we must consider that differences in exposure time could influence toxicity response. McPherson and Chapman (2000) reviewed the sensitivity differences among species for copper, and recommended that databases should be as fully developed as possible for common test species detailing their relative sensitivities to a range of organic and inorganic substances and concluded that species could be chosen to toxicity tests according to their sensitivity for each group or substance.

Toxicity of $\mathrm{Ag}$ to adults of $P$. hawaiensis was higher at salinity 5 than 30 , with LC50 values of 0.05 and $0.88 \mathrm{mg} \mathrm{L}^{-1}$, respectively, which was lower than LC50 of $1.1 \mathrm{mg} \mathrm{L}^{-1}$ observed for juveniles of $P$. hawaiensis reported by Artal et al. (2018) at salinity 30 . Lower metal toxicity at higher salinities has been well described in the literature (Ward \& Kramer, 2002; Verslycke et al., 2003; Leonard et al., 2011) and were already reported during zinc exposure for $P$. hawaiensis (Artal et al., 2018). Free silver ion $\left(\mathrm{Ag}^{+}\right)$is the main species responsible for Ag toxicity in the aqueous phase, belonging to the highest toxicity class together with $\mathrm{Cd}, \mathrm{Cr}(\mathrm{VI})$ and $\mathrm{Hg}$ (Ratte, 1999 and references therein). In marine environments, high salinity reduces free ionic metals concentrations, mainly because of their complexation with $\mathrm{Cl}^{-}$, decreasing the bioavailability of these elements (Verslycke et al., 2003). Indeed, the inorganic equilibrium speciation of $\mathrm{Ag}$ in seawater $(\mathrm{pH}=8$; salinity $=$ 33 ) is only $0.002 \%$ of the inorganic $\mathrm{Ag}$ as $\mathrm{Ag}^{+}$, contrasting to almost $100 \%$ for species of $\mathrm{AgCl}$ (Turner et al., 2012). Thus, the effects of silver contamination in marine environments are 
Table 1. Acute toxicity data (96-h LC50) for different substances to juveniles and adults of Parhyale hawaiensis.

\begin{tabular}{|c|c|c|c|}
\hline Chemical and purity & $\begin{array}{c}\text { Organisms } \\
\text { age }\end{array}$ & Salinity & $\operatorname{LC50}(95 \% \mathrm{CI})\left(\mathrm{mg} \mathrm{L}^{-1}\right)$ \\
\hline $\mathrm{ZnSO}_{4} \cdot 7 \mathrm{H}_{2} \mathrm{O}(\geq 99 \%)$ & $<7$ days & 30 & $1.73(1.42-2.09) *(n=8)$ \\
\hline $\mathrm{Cd}\left(\mathrm{NO}_{3}\right)_{2}(99 \%)$ & $<7$ days & 30 & $0.45(0.36-0.55) *(n=7)$ \\
\hline $\mathrm{CuCl}_{2} \cdot 2 \mathrm{H}_{2} \mathrm{O}(\geq 99 \%)$ & $<7$ days & 30 & $2.46(1.89-3.24) *(n=6)$ \\
\hline $\mathrm{AgNO}_{3}(\geq 99 \%)$ & 8 months & 30 & $0.88(0.40-1.98) *(n=2)$ \\
\hline $\mathrm{AgNO}_{3}(\geq 99 \%)$ & 8 months & 5 & $0.05(0.02-0.14) *(n=2)$ \\
\hline Disperse Red $1(60 \%)$ & $<7$ days & 30 & $22.5(10.5-51.5)^{*}(\mathrm{n}=3)$ \\
\hline Disperse Red 13 (25\%) & $<7$ days & 30 & $2.37(1.31-4.46) *(n=3)$ \\
\hline Pirimiphos-methil (>98\%) & $<7$ days & 30 & $0.34(0.22-0.50) *(n=2)$ \\
\hline
\end{tabular}

*Lethal concentration (LC50) and confidence interval (CI) were estimated based on the logistic regression curve of the combined data of independent tests (n). LC50 for metals are expressed in ion nominal concentration.

expected to occur in higher concentrations than in freshwater (Luoma et al., 1995; Bury et al., 2002). Pedroso et al. (2007) investigated effects of 48-h silver exposure in the euryhaline copepod Acartia tonsa in a range of salinities from 5 to 30 and reported that acute silver exposure significantly reduced the whole-body magnesium concentration and inhibited the $\mathrm{Na}^{+}, \mathrm{K}^{+}$-ATPase activity and these effects were similar in all salinities tested.

C. I. Disperse Red 13 was more toxic than C. I. Disperse Red 1 for P. hawaiensis with LC50 values of 2.37 and 22.5 $\mathrm{mg} \mathrm{L}^{-1}$, respectively. This result is consistent with those presented by Ferraz et al. (2011), who investigated the same dyes for Daphnia similis, and suggested that the addition of chlorine atom into the molecule of C. I. Disperse 13 increased toxicity of this dye. Yu et al. (2015) investigated the role of Cytochrome P450 (CYP) and Glutathione S-transferase (GST) enzymes in the metabolism of C.I. Disperse Red 1 in D. similis and showed that exposure to the dye induces GST activity and its induction seems to be dependent on CYP activity, since treatment with CYP inhibitor, blocked the DR1-dependent GST induction. Unfortunately, no comparable toxicity data for marine organisms and C. I. Disperse Red 1 and 13 are available in the literature and more studies are necessary to understand the toxicity effects and mode of action of disperse dyes in marine organisms.

Pesticide pirimiphos-methyl was the most toxic substance tested for $P$. hawaiensis in this study with a LC50 of $0.34 \mathrm{mg}$ $\mathrm{L}^{-1}$. In literature no data was found on toxicity of this substance to marine organisms. But it has been evaluated for freshwater organisms such as algae, daphnia, fish, and the freshwater amphipod Gammarus pulex (McLoughlin et al., 2000; Lewis et al., 2016). The LC50 reported for G. pulex was $2.78 \mu \mathrm{g}$ $\mathrm{L}^{-1}$ (McLoughlin et al., 2000), value 100x lower than it was observed for $P$. hawaiensis. In addition, the same authors investigated the effects on cholinesterase (ChE) activity and feeding rate in G. pulex exposed to pirimiphos-methyl and showed that this pesticide caused a change in the ChE activity of $G$. pulex, with significant reductions in enzyme activity occurring after 24-h and 48-h exposures to 1.92 and $0.77 \mu \mathrm{g} \mathrm{L}^{-1}$, respectively. Also feeding rate was significantly reduced after six days of exposure to $0.6 \mu \mathrm{g} \mathrm{L}^{-1}$ (McLoughlin et al., 2000). Thus, more studies are necessary to evaluate the toxicity of pirimiphos-methyl for marine organisms and to elucidate mechanisms and mode of action of this toxicant.

Effects observed for the tested substances with Nitocra sp. were described in Table 2 (see Supplemental Data II for raw data). LC50 of zinc to Nitocra sp. was $0.69 \mathrm{mg} \mathrm{L}^{-1}$ that was more sensitive than the result reported for $P$. hawaiensis in this study and by Artal et al. (2018) that were 1.73 and $1.1 \mathrm{mg} \mathrm{L}^{-1}$ in salinity 30 , respectively. In addition to species sensitivity, lower salinity used in toxicity test with Nitocra sp. compared to $P$. hawaiensis can be responsible for higher sensitivity to zinc. Nitocra sp. was also the most sensitive organism when compared to different copepods found in the literature. The LC50 reported for zinc to Nitocra spinipes varied from 0.89 to $4.3 \mathrm{mg} \mathrm{L}^{-1} \mathrm{Zn}$ (Bengtsson, 1978; Linden et al., 1979; Ytreberg et al., 2010). For both endpoints assessed for zinc, mortality and hatching success, the results were similar for LC50 and NOEC, 0.69 and $0.5 \mathrm{mg} \mathrm{L}^{-1} \mathrm{Zn}$, respectively. EC10 value estimated for zinc was $0.02 \mathrm{mg} \mathrm{L}^{-1}$, lower than the estimated NOEC. For zinc, Nitocra sp. and $P$. hawaiensis were within the range of sensitivity response of other organisms (Figure 1), and Nitocra sp. a is one of the most sensitive species just behind the clam Mercenaria mercenaria, the mysid shrimp Americamys bahia and the oyster Crassostrea virginica. 
Table 2. Toxicity data on mortality and embryo hatching success for different substances in toxicity tests with Nitocra sp. in salinity 20.

\begin{tabular}{|c|c|c|c|c|}
\hline Chemical and purity & Endpoint & $\begin{array}{c}\text { NOEC } \\
(\mathbf{m g} \\
\left.\mathbf{L}^{-1}\right)\end{array}$ & $\begin{array}{l}\operatorname{EC10}(95 \% \\
\text { CI) }\left(\mathrm{mg} \mathrm{L} \mathrm{L}^{-1}\right)\end{array}$ & $\begin{array}{c}\text { LC50 }(95 \% \mathrm{CI}) \\
\left(\mathrm{mg} \mathrm{L}^{-1}\right)\end{array}$ \\
\hline $\mathrm{ZnSO}_{4} \cdot 7 \mathrm{H}_{2} \mathrm{O}(\geq 99 \%)$ & Mortality & - & - & $\begin{array}{c}0.69(0.60-0.78) * \\
(n=18)\end{array}$ \\
\hline $\mathrm{ZnSO}_{4} \cdot 7 \mathrm{H}_{2} \mathrm{O}(\geq 99 \%)$ & $\begin{array}{l}\text { Embryo } \\
\text { hatching } \\
\text { success }\end{array}$ & $\begin{array}{c}0.5 \\
(\mathrm{n}=1)\end{array}$ & $\begin{array}{c}0.02 \\
\left(5 \times 10^{-6}-0.2\right)\end{array}$ & - \\
\hline Disperse Red 1 (60\%) & Mortality & - & - & $\begin{array}{c}2.04(1.47-2.81)^{*} \\
(\mathrm{n}=3)\end{array}$ \\
\hline Disperse Red 1 (60\%) & $\begin{array}{l}\text { Embryo } \\
\text { hatching } \\
\text { success }\end{array}$ & $\begin{array}{c}0.1 \\
(\mathrm{n}=1)\end{array}$ & $\begin{array}{c}0.02 \\
\left(2 \times 10^{-6}-0.4\right)\end{array}$ & - \\
\hline Disperse Red 13 (25\%) & Mortality & - & - & $\begin{array}{c}1.78(1.30-2.43)^{*} \\
(\mathrm{n}=2)\end{array}$ \\
\hline Disperse Red 13 (25\%) & $\begin{array}{l}\text { Embryo } \\
\text { hatching } \\
\text { success }\end{array}$ & $\begin{array}{c}1.0 \\
(\mathrm{n}=1)\end{array}$ & $\begin{array}{c}0.8 \\
(0.3-1.5)\end{array}$ & - \\
\hline
\end{tabular}

*Lethal concentration (LC50) and confidence interval (CI) were estimated based on the logistic regression curve of the combined data of independent tests (n). LC50 and EC10 (10\% effective concetration) for metals are expressed in ion nominal concentration.

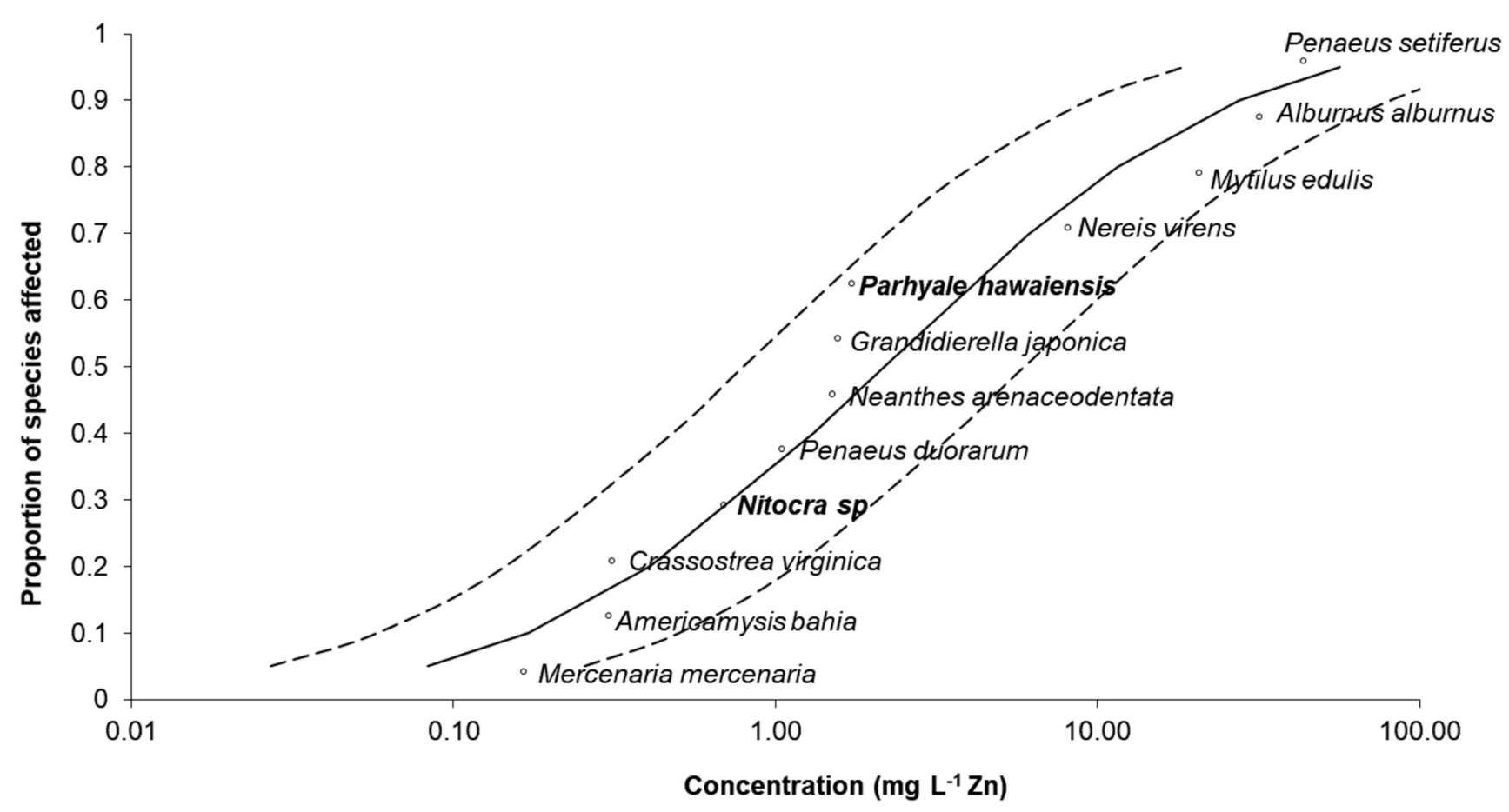

Figure 1. Species sensitivity distribution of zinc for saltwater species. Flat curve (log-logistic regressions) are based on acute LC50-values and dashed lines represent the 95\% confidence intervals. For Parhyale hawaiensis and Nitocra sp., in bold letter, LC50 values were obtained in this study and USEPA database were used as a source for the other species. 
Toxicity of C. I. Disperse Red 1 and C. I. Disperse Red 13 for Nitocra sp. were similar, with LC50s of 2.04 and $1.78 \mathrm{mg}$ $\mathrm{L}^{-1}$, respectively. However, C.I. Disperse Red 1 was 10 times more toxic than C.I. Disperse Red 13 in the hatching success endpoint, with NOEC values of 0.1 and $1 \mathrm{mg} \mathrm{L}^{-1}$, respectively (Table 2). EC10 value estimated for C.I. Disperse Red 1 was $0.02 \mathrm{mg} \mathrm{L}^{-1}$ value $5 \mathrm{x}$ lower than NOEC and for C.I. Disperse Red 13 the EC10 was $0.8 \mathrm{mg} \mathrm{L}^{-1}$, consistent with the obtained NOEC of $1 \mathrm{mg} \mathrm{L}^{-1}$. Comparing values of LC50 for mortality and NOEC for hatching success obtained for Disperse Red 1, NOEC was 20x lower than LC50. However, comparing values of NOEC in hatching success and LC50 in mortality with Nitocra sp. for Disperse Red 13 and zinc, values were in the same range (Table 2). NOEC and LC50 were 0.5 and 0.69 $\mathrm{mg} \mathrm{L}^{-1}$ for zinc, and 1.0 and $1.78 \mathrm{mg} \mathrm{L}^{-1}$ for Disperse Red 13, respectively. Considering that eggs are carried by females in ventral sac until they hatch a thin laid of the sac and eggs could protect the embryos from chemicals exposure. Accordingly, Gorbi et al., (2012) presented a proposal for standardization of tests using the calanoid copepod Acartia tonsa and the methodology consists in the application of embryos exposure, because the naupliar stages are more sensitive than the responses obtained for the immobility of adults and the hatching of eggs. Moreover, Buttino et al. (2010) suggested that even with no effect or change in hatching success, nauplii may exhibit effects and deformation after hatching that would compromise the population's prosperity in their habitat. Therefore, the use of egg hatching success as endpoint could be reviewed and replace by more sensitivities responses.

Hall \& Anderson (1995) reviewed the literature to evaluate the effects of salinity on the toxicity of different classes of inorganic and organic chemicals. They found that the majority of the studies (70\%) reported that as the salinity increases, toxicity decreases. Particularly metals demonstrated a strong negative correlation between salinity and toxicity while organic chemicals do not result in consistent correlation for the toxicity with salinity. The exception to this was organophosphate insecticides, which appeared to has its toxicity increased with increasing salinity. Authors highlighted that physiological and ecological characteristics of the test species are important in determining the toxicity of the various classes of chemicals at a range of salinities. The role of salinity and sensitivity of different compounds for $P$. hawaiensis and Nitocra sp. needs to be further investigated, but the possibility to test and use these organisms in different salinities open the frames for other studies with Braziliabn representative species.

\section{CONCLUSIONS}

This study provided toxicity data on the literature of marine organisms, mainly for the substances for which toxicity data are not available (disperse dyes and pirimiphos-methyl). Results demonstrated that $P$. hawaiensis and Nitocra sp. are suitable organisms for ecotoxicity evaluation, given that their sensitivities are the range of other marine species. Nitocra sp. was more sensitive than other copepods to zinc, and more sensitive than $P$. hawaiensis to disperse dyes. Sensitivity species distribution showed that Nitocra sp. and P. hawaiensis were within the sensitivity of other species to zinc, and the copepod is among of the most sensitive species. Moreover, our findings highlighted that more studies need to be carried out to assess the toxicity of different substances to marine and estuarine organisms' representative from tropical ecosystems.

\section{ACKNOWLEDGEMENTS}

This study was founded by the São Paulo Research Foundation - FAPESP (grants number: 2010/14033-0 to M.C.A.; 2012/09512-1 to A.S; 2013/26301-7 to M.V.; and grant 2008/10449-7), the Brazilian National Council for Scientific and Technological Development - CNPq (grant number 400362/2014-7). This a contribution of Millennium Institute of Complex Materials and National Institute for Science and Technology and Innovation of Functional Complex Materials (INOMAT) and this study was financed in part by the Coordenação de Aperfeiçoamento de Pessoal de Nível Superior (CAPES) - Finance Code 001. We also thank M. Flynn, A. Caloto-Oliveira and G. Almeida for P. hawaiensis collection, F. Leite and S.L. Gomes for the organism identification; and L. P. Zaroni and E.C.P.M. Sousa who kindly provided Nitocra sp. to our laboratory.

\section{REFERENCES}

ABNT. 2016. Ecotoxicologia aquática - Toxicidade aguda - Método de ensaio com anfípodos marinhos e estuarinos em sedimentos. Associação Brasileira de Normas Técnicas. ABNT NBR 15638. Rio de Janeiro, Brasil.

Artal, M. C., dos Santos, A., Henry, T. B., \& Umbuzeiro, G. D. A. 2018. Development of an acute toxicity test with the tropical marine amphipod Parhyale hawaiensis. Ecotoxicology, 27(2), 103-108. https://doi.org/10.1007/s10646-017-1875-3

Asghari, S., Johari, S. A., Lee, J. H., Kim, Y. S., Jeon, Y. B., Choi, H. J., ET AL. 2012. Toxicity of various silver nanoparticles compared to silver ions in Daphnia magna. Journal of Nanobiotechnology, 10, 14. https://doi.org/10.1186/1477-3155-10-14

Bengtsson, B.-E. 1978. Use of a harpacticoid copepod in toxicity tests. Marine Pollution Bulletin, 9(9), 238-241. https://doi. org/10.1016/0025-326X(78)90378-8

Bury, N. R., Shaw, J., Glover, C., \& Hogstrand, C. 2002. Derivation of a toxicity-based model to predict how water chemistry influences silver toxicity to invertebrates. Comparative Biochemistry and Physiology - C Toxicology and Pharmacology, 133(1-2), 259-270. https://doi.org/10.1016/ S1532-0456(02)00096-0

Buttino, I., Hwang, J.-S., Sun, C.-K., Hsieh, C.-T., Liu, T.-M., Pellegrini, D., et AL. 2010. Apoptosis to predict copepod mortality: state of the art and future perspectives. Hydrobiologia, 666(1), 257-264. https://doi.org/10.1007/s10750-010-0536-9

Charles, S., Veber, P., \& Laure, M. 2017. MOSAIC : a webinterface for statistical analyses in ecotoxicology. Environ Sci Pollut Res. https://doi.org/10.1007/s11356-017-9809-4

DaAm, M. A., \& Brink, P. J. VAn Den. 2010. Implications of differences between temperate and tropical freshwater ecosystems 
for the ecological risk assessment of pesticides. Ecotoxicology, 24-37. https://doi.org/10.1007/s10646-009-0402-6

Ferraz, E. R. A., Umbuzeiro, G. A., De-Almeida, G., CalotoOliveira, A., Chequer, F. M. D., Zanoni, M. V. B., ET AL. 2011. Differential toxicity of Disperse Red 1 and Disperse Red 13 in the Ames test, HepG2 cytotoxicity assay, and Daphnia acute toxicity test. Environmental Toxicology, 26(5), 489-497. https:// doi.org/10.1002/tox.20576

Gorbi, G., Invidia, M., Savorelli, F., Faraponova, O., Giacco, E., Cigar, M., ET AL. 2012. Standardized methods for acute and semichronic toxicity tests with the copepod Acartia tonsa. Environmental Toxicology and Chemistry / SETAC, 31(9), 2023-8. https://doi.org/10.1002/etc.1909

Hall, L. W., \& Anderson, R. D. 1995. The Influence of Salinity on the Toxicity of Various Classes of Chemicals to Aquatic Biota. Critical Reviews in Toxicology, 25(4), 281-346.

Kao, D., Lai, A. G., Stamataki, E., Rosic, S., Konstantinides, N., JARVIS, E., ET AL. 2016. The genome of the crustacean Parhyale hawaiensis, a model for animal development, regeneration, immunity and lignocellulose digestion. ELife, 5, 065789. https:// doi.org/10.7554/eLife.20062

King, C. K., Gale, S. A., \& Stauber, J. L. 2006a. Acute Toxicity and Bioaccumulation of Aqueous and Sediment-Bound Metals in the Estuarine Amphipod Melita plumulosa. Environmental Toxicology, 489-504. https://doi.org/10.1002/tox

King, C. K., Gale, S. A., Hyne, R. V, Stauber, J. L., Simpson, S. L., \& Hickey, C. W. 2006b. Sensitivities of Australian and New Zealand amphipods to copper and zinc in waters and metalspiked sediments. Chemosphere, 63(9), 1466-1476. https://doi. org/10.1016/j.chemosphere.2005.09.020

Klok, C., De VRies, P., Jongbloed, R., \& Tamis, J. 2012. Literature review on the sensitivity and exposure of marine and estuarine organisms to pesticides in comparison to corresponding fresh water species. EFSA Supporting Publications, 9(11), 152. https:// doi.org/10.2903/sp.efsa.2012.EN-357

Krull, M., \& Barros, F. 2012. Key Issues in Aquatic Ecotoxicology in Brazil : A Critical Review. Journal of the Brazilian Society of Ecotoxicology, 7(2), 57-66. https://doi.org/10.5132/ jbse.2012.02.009

Kwok, K. W., Leung, K. M., Lui, G. S., Chu, V. K., Lam, P. K., MorritT, D., ET AL. 2007. Comparison of tropical and temperate freshwater animal species' acute sensitivities to chemicals: Implications for deriving safe extrapolation factors. Integrated Environmental Assessment and Management, 3(1), 49-67. https://doi.org/10.1002/ieam.5630030105

Leonard, E. M., Barcarolli, I., Silva, K. R., Wasielesky, W., Wood, C. M., \& BiANCHINI, A. 2011. The effects of salinity on acute and chronic nickel toxicity and bioaccumulation in two euryhaline crustaceans: Litopenaeus vannamei and Excirolana armata. Comparative Biochemistry and Physiology - C Toxicology and Pharmacology, 154(4), 409-419. https://doi.org/10.1016/j. cbpc.2011.07.011

Lewis, K. A., Tzilivakis, J., Warner, D., \& Green, A. 2016. An international database for pesticide risk asses sments and management. Human and Ecological Risk Assessment: An International Journal. https://doi.org/10.1080/10807039.2015.1133242

Linden, E., Bengtsson, B.-E., Svanberg, O., \& Sundstrom, G. 1979. The acute toxicity of 78 chemicals and pesticide formulations against two brackish water organisms, the bleak (Alburnus alburnus) and the harpacticoid Nitocra spinipes. Chemosphere, 8(11-12), 843-851. https://doi.org/10.1016/00456535(79)90015-8

Lotufo, G. R., \& Abessa, D. M. S. 2002. Testes de toxicidade com sedimento total e água intersticial estuarinos utilizando copépodos bentônicos. In I. A. Nascimento, E. C. P. M. Sousa, \& M. Nipper (Eds.), Métodos em Ecotoxicologia Marinha: Aplicações no Brasil (pp. 151-162). São Paulo: Editora Artes Gráficas e Indústria Ltda.

Luoma, S. N., Ho, Y. B., \& Bryan, G. W. 1995. Fate, bioavailability and toxicity of silver in estuarine environments. Marine Pollution Bulletin, 31(1-3), 44-54. https://doi.org/10.1016/0025326X(95)00081-W

MAPA. 2019. Ministério da Agricultura, Pecuária e Abastecimento, Sistemas de Agrotóxicos Fitossanitários. AGROFIT. Retrieved January 28, 2019, from http://agrofit.agricultura.gov.br

McGee, B. L., Wright, D. A., \& Fisher, D. J. 1998. Biotic factors modifying acute toxicity of aqueous cadmium to estuarine amphipod Leptocheirus plumulosus. Archives of Environmental Contamination and Toxicology, 34(1), 34-40. https://doi. org/10.1007/s002449900283

Mcloughlin, N., Yin, D., Maltby, L., Wood, R. M., \& Yu, H. 2000. Evaluation of sensitivity and specificity of two crustacean biochemical biomarkers. Environmental Toxicology and Chemistry, 19(8), 2085-2092. https://doi.org/10.1002/ etc. 5620190818

McPherson, C. A., \& Chapman, P. M. 2000. Copper effects on potential sediment test organisms: the importance of appropriate sensitivity. Marine Pollution Bulletin, 40(8), 656-665. https:// doi.org/10.1016/S0025-326X(00)00043-6

Melo, S. L. R., \& Nipper, M. 2007. Sediment toxicity tests using the burrowing amphipod Tiburonella viscana (Amphipoda: Platyischnopidae). Ecotoxicology and Environmental Safety, 66(3), 412-20. https://doi.org/10.1016/j.ecoenv.2005.12.003

Pedroso, M. S., Pinho, G. L. L., Rodrigues, S. C., \& Bianchini, A. 2007. Mechanism of acute silver toxicity in the euryhaline copepod Acartia tonsa. Aquatic Toxicology (Amsterdam, Netherlands), $82(3), \quad$ 173-80. https://doi.org/10.1016/j. aquatox.2007.02.009

R Core Team. 2017. R: A language and environment for statistical computing. Vienna, Austria: R Foundation for Statistical Computing. Retrieved from https://www.r-project.org/

RATTE, H. T. 1999. Bioaccumulation and toxicity of silver compounds: a review. Environmental Toxicology and Chemistry, 18(1), 89108. https://doi.org/10.1002/etc.5620180112

Ribeiro, A., \& Umbuzeiro, G. 2014. Effects of a textile azo dye on mortality, regeneration, and reproductive performance of the planarian, Girardia tigrina. Environmental Sciences Europe, 26(1), 22. https://doi.org/10.1186/s12302-014-0022-5

Seabra, C. D., Maranho, L. A., Cortez, F. S., Pusceddu, F. H., Santos, A. R., Ribeiro, D. A., ET AL. 2016. Occurrence of pharmaceuticals and cocaine in a Brazilian coastal zone. Science of the Total Environment, The, 549, 148-154. https://doi. org/10.1016/j.scitotenv.2016.01.051

Sousa, E. C. P. M. De, Zaroni, L. P., Gasparro, M. R., \& Pereira, C. D. S. 2014. Review of Ecotoxicological Studies of the Marine and Estuarine Environments of the Baixada Santista (Sao Paulo, Brazil). Brazilian Journal of Oceanography, 62(2), 133-147. https://doi.org/10.1590/s1679-87592014063006202

Sousa, E. C. P. M. De, Zaroni, L. P., Bergmann Filho, T. U., Marconato, L. A., Kirschbaum, A. A., \& Gasparro, M. R. 2012. Acute sensitivity to Nitokra sp benthic copepod to potassium dichromate and ammonia chloride. J. Braz. Soc. Ecotoxicol., 7(1), 75-81. https://doi.org/10.5132/jbse.2012.01.011

Teklu, B. M., Retta, N., \& VAN DEN Brink, P. J. 2016. Sensitivity of Ethiopian aquatic macroinvertebrates to the pesticides endosulfan and diazinon, compared to literature data. Ecotoxicology, 25(6), 1226-1233. https://doi.org/10.1007/s10646-016-1676-0

Turner, A., Brice, D., \& Brown, M. T. 2012. Interactions of silver nanoparticles with the marine macroalga, Ulva lactuca. Ecotoxicology, 21(1), 148-154. https://doi.org/10.1007/s10646- 
011-0774-2

USEPA, (Environmental Protection Agency). 2017. Causal Analysis/Diagnosis Decision Information System (CADDIS): Species Sensitivity Distribution Generator - Version 1. Retrieved February 11, 2019, from https://www.epa.gov/caddis-vol4/ caddis-volume-4-data-analysis-download-software

USEPA, (Environmental Protection Agency). 2019. ECOTOX: Ecotoxicology Knowledgebase system - Version 5. Retrieved January 18, 2019, from http://www.epa.gov/ecotox/

Vacchi, F. I., Albuquerque, A. F., Vendemiatti, J. A., Morales, D. A., Ormond, A. B., Freeman, H. S., et Al. 2013. Chlorine disinfection of dye wastewater: implications for a commercial azo dye mixture. The Science of the Total Environment, 442, 302-309. https://doi.org/10.1016/j.scitotenv.2012.10.019

Vacchi, F. I., Von der Ohe, P. C., Albuquerque, A. F. De, Vendemiatti, J. A. de S., Azevedo, C. C. J., Honório, J. G., et AL. 2016. Occurrence and risk assessment of an azo dye - The case of Disperse Red 1. Chemosphere, 156, 95-100. https://doi. org/10.1016/j.chemosphere.2016.04.121

Vannuci-Silva, M., Silva, E. do N., Artal, M. C., Santos, A. dos, Silva, F., Umbuzeiro, G. DE A., \& Cadore, S. 2018. GFAAS and ICP-MS Determination of $\mathrm{Ag}$ and $\mathrm{Cu}$ in the Haemolymph of a Millimetric Marine Crustacean ( Parhyale hawaiensis ) as a Tool in Ecotoxicology. Atomic Spectroscopy, 39(2), 67-74.

\section{SUPPLEMENTAL DATA I - Parhyale hawaiensis}

Table 1. Raw data of zinc exposure to neonates of Parhyale hawaiensis.

\begin{tabular}{lcccccccc} 
& \multicolumn{8}{c}{ Mortality } \\
\cline { 2 - 9 } Concentration & Test & Test & Test & Test & Test & Test & Test & Test \\
$\left(\mathrm{mg} \mathrm{L}^{-1}\right) \mathrm{Zn}$ & 1 & 2 & 3 & 4 & 5 & 6 & 7 & 8 \\
\hline 0 & 1 & 0 & 1 & 1 & 0 & 1 & 0 & 1 \\
0.125 & 1 & - & - & - & - & - & - & - \\
0.25 & 1 & 0 & 0 & 1 & 1 & 0 & 0 & 2 \\
0.5 & 5 & 2 & 2 & 4 & 3 & 3 & 1 & 1 \\
1 & 13 & 12 & 7 & 10 & 11 & 12 & 10 & 9 \\
2 & 20 & 20 & 16 & 23 & 17 & 21 & 23 & 14 \\
4 & - & 32 & 30 & 32 & 29 & 31 & 32 & 31 \\
\hline
\end{tabular}

Number of exposed organisms $=32$

Table 2. Raw data of cadmium exposure to neonates of Parhyale hawaiensis.

\begin{tabular}{lccccccc} 
& \multicolumn{7}{c}{ Mortality } \\
\hline Concentration & Test & Test & Test & Test & Test & Test & Test \\
$\left(\mathrm{mg} \mathrm{L}^{-1}\right) \mathrm{Cd}$ & 1 & 2 & 3 & 4 & 5 & 6 & 7 \\
\hline 0 & 2 & 2 & 0 & 0 & 1 & 1 & 2 \\
0.1 & 1 & 2 & 0 & 1 & 2 & 1 & 4 \\
0.2 & 2 & 8 & 2 & 4 & 2 & 2 & 3 \\
0.3 & - & - & 8 & 12 & 8 & 14 & 11 \\
0.4 & 16 & 21 & 15 & 22 & 13 & 17 & 19 \\
0.8 & 26 & 31 & 24 & 28 & 25 & 29 & 29 \\
1.6 & 32 & 32 & - & - & - & - & - \\
\hline
\end{tabular}

Number of exposed organisms $=32$
Vannuci-Silva, M., Cadore, S., Henry, T. B., \& Umbuzeiro, G. D. A. 2019. Higher Ag bioavailability after nanoparticles dietary exposure in marine amphipods. Environ. Toxicol. Chem., 1-21. https://doi.org/10.1002/etc.4359

Verslycke, T., Vangheluwe, M.,Heijerick,D.,De Schamphelaere, K., Van Sprang, P., \& Janssen, C. R. 2003. The toxicity of metal mixtures to the estuarine mysid Neomysis integer (Crustacea: Mysidacea) under changing salinity. Aquatic Toxicology, 64(3), 307-315. https://doi.org/10.1016/S0166-445X(03)00061-4

WARD, T. J., \& KRAmer, J. R. 2002. Silver speciation during chronic toxicity tests with the mysid, Americamysis bahia. Comparative Biochemistry and Physiology Part C: Toxicology \& Pharmacology, 133(1-2), 75-86. https://doi.org/10.1016/ S1532-0456(02)00082-0

Ytreberg, E., Karlsson, J., \& Eklund, B. 2010. Comparison of toxicity and release rates of $\mathrm{Cu}$ and $\mathrm{Zn}$ from anti-fouling paints leached in natural and artificial brackish seawater. Science of the Total Environment, 408(12), 2459-2466. https://doi. org/10.1016/j.scitotenv.2010.02.036

Yu, T. H., Dafre, A. L., de Aragão Umbuzeiro, G., \& Franciscon, E. 2015. CYP-dependent induction of glutathione S-transferase in Daphnia similis exposed to a disperse azo dye. Ecotoxicology, 24(1), 232-237. https://doi.org/10.1007/s10646-014-1348-x

Table 3. Raw data of copper exposure to neonates of Parhyale hawaiensis.

\begin{tabular}{lcccccc}
\cline { 2 - 7 } & \multicolumn{7}{c}{ Mortality } \\
\hline Concentration & Test & Test & Test & Test & Test & Test \\
$\left(\mathrm{mg} \mathrm{L}^{-1}\right) \mathrm{Cu}$ & 1 & 2 & 3 & 4 & 5 & 6 \\
0 & 1 & 0 & 1 & 1 & 0 & 0 \\
0.2 & 5 & 3 & 5 & 4 & 5 & 4 \\
0.4 & 6 & 5 & 7 & 8 & 6 & 9 \\
0.8 & 10 & 8 & 8 & 11 & 7 & 10 \\
1.6 & 12 & 14 & 13 & 15 & 12 & 13 \\
3.2 & 17 & 20 & 17 & 21 & 19 & 18 \\
\hline
\end{tabular}

Number of exposed organisms $=32$

Table 4. Raw data of silver exposure to adults of Parhyale hawaiensis at salinity 30 .

\begin{tabular}{lccc}
\cline { 2 - 4 } $\begin{array}{l}\text { Concentration } \\
\left(\mathrm{mg} \mathrm{L}^{-1}\right)\end{array}$ & Test 1 & $\begin{array}{c}\text { Concentration } \\
\left(\mathrm{mg} \mathrm{L}^{-1}\right)\end{array}$ & Test 2 \\
\hline 0 & 0 & 0 & 0 \\
0.001 & 0 & 0.25 & 0 \\
0.01 & 0 & 0.5 & 3 \\
0.1 & 0 & 1 & 8 \\
1 & 6 & 2 & 9 \\
10 & 10 & 4 & 10 \\
- & - & 8 & 10 \\
\hline
\end{tabular}

Number of exposed organisms $=10$ 
Table 5. Raw data of silver exposure to adults of Parhyale hawaiensis at salinity 5 .

\begin{tabular}{lcc} 
& Mortality & Mortality \\
\hline Concentration & Test 1 & Test 2 \\
$\left(\mathrm{mg} \mathrm{L}^{-1}\right) \mathrm{Ag}$ & & 0 \\
\hline 0 & 1 & 0 \\
0.025 & 1 & 2 \\
0.05 & - & - \\
0.08 & 9 & 6 \\
0.1 & - & 6 \\
0.2 & - & - \\
0.25 & 10 & \\
\hline
\end{tabular}

Number of exposed organisms $=10$ at test 1 and 6 at test 2

Table 6. Raw data of C. I. Disperse Red 1 exposure to neonates of Parhyale hawaiensis.

\begin{tabular}{lccc} 
& \multicolumn{3}{c}{ Mortality } \\
\hline Concentration & Test & Test & Test \\
$\left(\mathrm{mg} \mathrm{L}^{-1}\right) \mathrm{DR} 1$ & 1 & 2 & 3 \\
\hline 0 & 0 & 0 & 0 \\
DMSO $(0.1 \%)$ & 0 & 0 & 0 \\
0.2 & 0 & 0 & 0 \\
1 & 4 & 1 & 2 \\
5 & 7 & 4 & 2 \\
25 & 7 & 7 & 6 \\
125 & 10 & 9 & 10 \\
\hline
\end{tabular}

Number of exposed organisms $=10$.

Table 7. Raw data of C. I. Disperse Red 13 exposure to neonates of Parhyale hawaiensis.

\begin{tabular}{lccc} 
& \multicolumn{3}{c}{ Mortality } \\
\hline Concentration & Test & Test & Test \\
$\left(\mathrm{mg} \mathrm{L}^{-1}\right)$ DR13 & 1 & 2 & 3 \\
\hline 0 & 0 & 0 & 0 \\
DMSO $(0.1 \%)$ & 0 & 0 & 0 \\
0.1 & 0 & 0 & 0 \\
0.3 & 0 & 0 & 1 \\
0.9 & 4 & 3 & 1 \\
2.7 & 8 & 7 & 2 \\
8.1 & 10 & 10 & 10 \\
\hline
\end{tabular}

Number of exposed organisms $=10$
Table 8. Raw data of pirimiphos-methyl exposure to neonates of Parhyale hawaiensis.

\begin{tabular}{lcc}
\cline { 2 - 3 } Concentration & \multicolumn{2}{c}{ Mortality } \\
\hline$\left(\mu \mathrm{g} \mathrm{L}^{-1}\right)$ & 1 & 2 \\
\hline 0 & 1 & 0 \\
DMSO $(0.008 \%)$ & 0 & 0 \\
100 & 4 & 6 \\
250 & 11 & 14 \\
500 & 24 & 27 \\
750 & 29 & 31 \\
1000 & 32 & 31 \\
\hline
\end{tabular}

Number of exposed organisms $=32$

\section{SUPPLEMENTAL DATA II - Nitocra sp.}

Table 1. Raw data of mortality from zinc exposure to Nitocra sp.

\begin{tabular}{lcccccc} 
& \multicolumn{7}{c}{ Mortality } \\
\hline Concentration & Test & Test & Test & Test & Test & Test \\
$\left(\mathrm{mg} \mathrm{L}^{-1}\right)$ & 1 & 2 & 3 & 4 & 5 & 6 \\
\hline 0 & 1 & 0 & 0 & 1 & 1 & 0 \\
0.1 & 2 & 0 & 0 & 0 & 6 & 2 \\
0.2 & 2 & 0 & 2 & 0 & 1 & 4 \\
0.6 & 1 & 1 & 3 & 9 & 17 & 4 \\
0.8 & - & - & - & 24 & 19 & - \\
1.1 & 24 & 19 & 29 & - & - & 22 \\
1.3 & - & - & - & 30 & 30 & - \\
2.3 & 30 & 30 & 30 & 30 & 30 & 30 \\
\hline
\end{tabular}

Number of exposed organisms $=30$

Table 2. Continue - Raw data of mortality from zinc exposure to Nitocra sp.

\begin{tabular}{lcccccc}
\cline { 2 - 7 } Concentration & Test & Test & Test & Test & Test & Test \\
$\left(\mathrm{mg} \mathrm{L}^{-1}\right)$ & 7 & 8 & 9 & 10 & 11 & 12 \\
\hline 0 & 1 & 0 & 3 & 0 & 1 & 1 \\
0.1 & 0 & 1 & 6 & - & 1 & 0 \\
0.2 & 1 & 2 & 8 & 2 & 2 & 9 \\
0.6 & 6 & 10 & 24 & 13 & 13 & 13 \\
0.8 & - & 15 & 26 & - & 27 & 19 \\
1.1 & 26 & - & - & - & - & - \\
1.3 & - & 24 & 30 & 29 & 30 & 30 \\
2.3 & 30 & 30 & 30 & 30 & 30 & 30 \\
\hline
\end{tabular}

Number of exposed organisms $=30$ 
Table 3. Continue - Raw data of mortality from zinc exposure to Nitocra sp.

\begin{tabular}{lcccccc} 
& \multicolumn{7}{c}{ Mortality } \\
\hline Concentration & Test & Test & Test & Test & Test & Test \\
$\left(\mathrm{mg} \mathrm{L}^{-1}\right)$ & 13 & 14 & 15 & 16 & 17 & 18 \\
\hline 0 & 1 & 1 & 0 & 0 & 0 & 0 \\
0.1 & 2 & 0 & 0 & 0 & 0 & 0 \\
0.2 & 7 & 1 & 0 & 1 & 3 & 0 \\
0.5 & - & - & - & 22 & 30 & 10 \\
0.6 & 19 & 4 & 7 & - & - & - \\
0.7 & - & - & - & 29 & 30 & - \\
0.8 & 24 & 5 & 7 & - & - & - \\
0.9 & & & & & & 30 \\
1.1 & - & - & - & 30 & 30 & - \\
1.3 & 30 & 16 & 28 & - & - & - \\
1.8 & - & - & - & - & - & 30 \\
2.3 & 30 & 30 & 29 & - & - & - \\
\hline
\end{tabular}

Number of exposed organisms $=30$

Table 4. Raw data of hatching success test with the number of hatched nauplii from zinc exposure to Nitocra sp.

\begin{tabular}{lc}
\cline { 2 - 2 } & Number of nauplii \\
\hline Concentration & Test 1 \\
\hline $\left.\mathrm{mg} \mathrm{L}^{-1}\right) \mathrm{Zn}$ & 64 \\
0 & 45 \\
0.11 & 45 \\
0.23 & 35 \\
0.46 & 33 \\
0.68 & 19 \\
1.14 & \\
\hline
\end{tabular}

Table 5. Raw data of mortality from C. I. Disperse Red 1 exposure to Nitocra sp.

\begin{tabular}{lccc}
\multicolumn{4}{c}{ Nitocra sp. } \\
\cline { 2 - 4 } Concentration & Test & Test & Test \\
$\left(\mathrm{mg} \mathrm{L}^{-1}\right) \mathrm{DR} 1$ & 1 & 2 & 3 \\
0 & 2 & 0 & 0 \\
0.05 & 1 & - & - \\
0.1 & 10 & 0 & 6 \\
0.5 & 34 & 7 & 19 \\
1 & 26 & 7 & 19 \\
2.5 & 29 & 23 & 20 \\
5 & 38 & 34 & 28 \\
\hline Number of exposed organisms $=40$
\end{tabular}

Table 6. Raw data of mortality from C. I. Disperse Red 13 exposure to Nitocra sp.

\begin{tabular}{lcc} 
& \multicolumn{2}{c}{ Mortality } \\
\hline Concentration & Test & Test \\
$\left(\mathrm{mg} \mathrm{L}^{-1}\right)$ DR13 & 1 & 2 \\
\hline 0 & 0 & 1 \\
0.01 & 0 & - \\
0.05 & 0 & - \\
0.1 & 2 & 8 \\
0.5 & 6 & 8 \\
1 & 8 & 8 \\
2.5 & 22 & 38 \\
5 & 40 & 40 \\
\hline Number of exposed organisms $=40$
\end{tabular}

Table 7. Raw data of hatching success test with the number of hatched nauplii from C. I. Disperse Red 1 and C. I. Disperse Red 13 exposure to Nitocra sp.

\begin{tabular}{lcc}
\cline { 2 - 3 } $\begin{array}{l}\text { Concentration } \\
\left(\mathrm{mg} \mathrm{L}^{-1}\right)\end{array}$ & C. I. Disperse Red 1 & C. I. Disperse Red 13 \\
\hline 0 & 64 & 86 \\
0.1 & 54 & 76 \\
1 & 34 & 86 \\
2 & 37 & 55 \\
3 & 27 & 38 \\
5 & 23 & 25 \\
\hline
\end{tabular}

